\title{
Global Magnetic Mapping of LIPs from EMAG2 version 3
}

T166. Large Igneous Provinces (LIPs) in the Solar System

Rick Saltus (rick,saltus@noaa.gov)

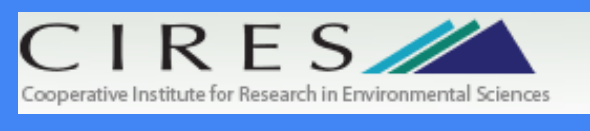

Gordi Oakey (gordon.oakey@canada.ca) Brian Meyer (brian.mever@noala.gov)
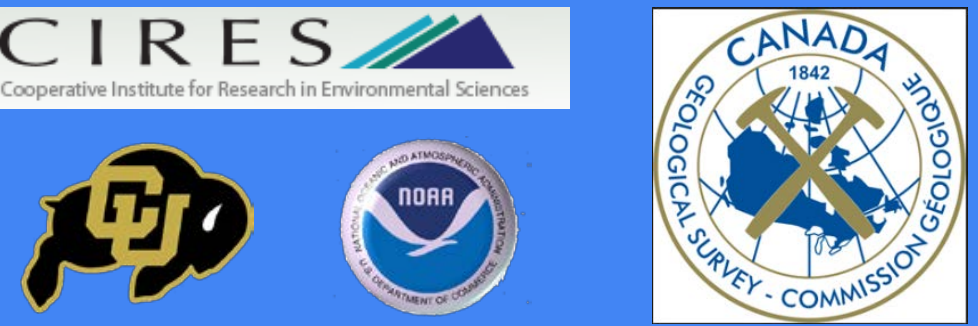


\section{Outline}

- EMAG2 version 3 (2016) - Global compilation of lithospheric magnetic anomalies

- Arctic magnetic anomalies and the High Arctic Large Igneous Province

- Other notable LJPs and their magnetic expression

- A first look at the global magnetic expression of LIPs

- Audience participation - Yes/No/Maybe vote 


\section{EMAG2 - Version 3}

- 2-Arc Minute $(\sim 4 \mathrm{~km})$ resolution

- Leveled to MF7 (long wavelength crustal anomaly field from satellite data)

- No a-priori ocean age model included

- Arctic from IPY CAMP-GM grid

- Antarctic from ADMAP

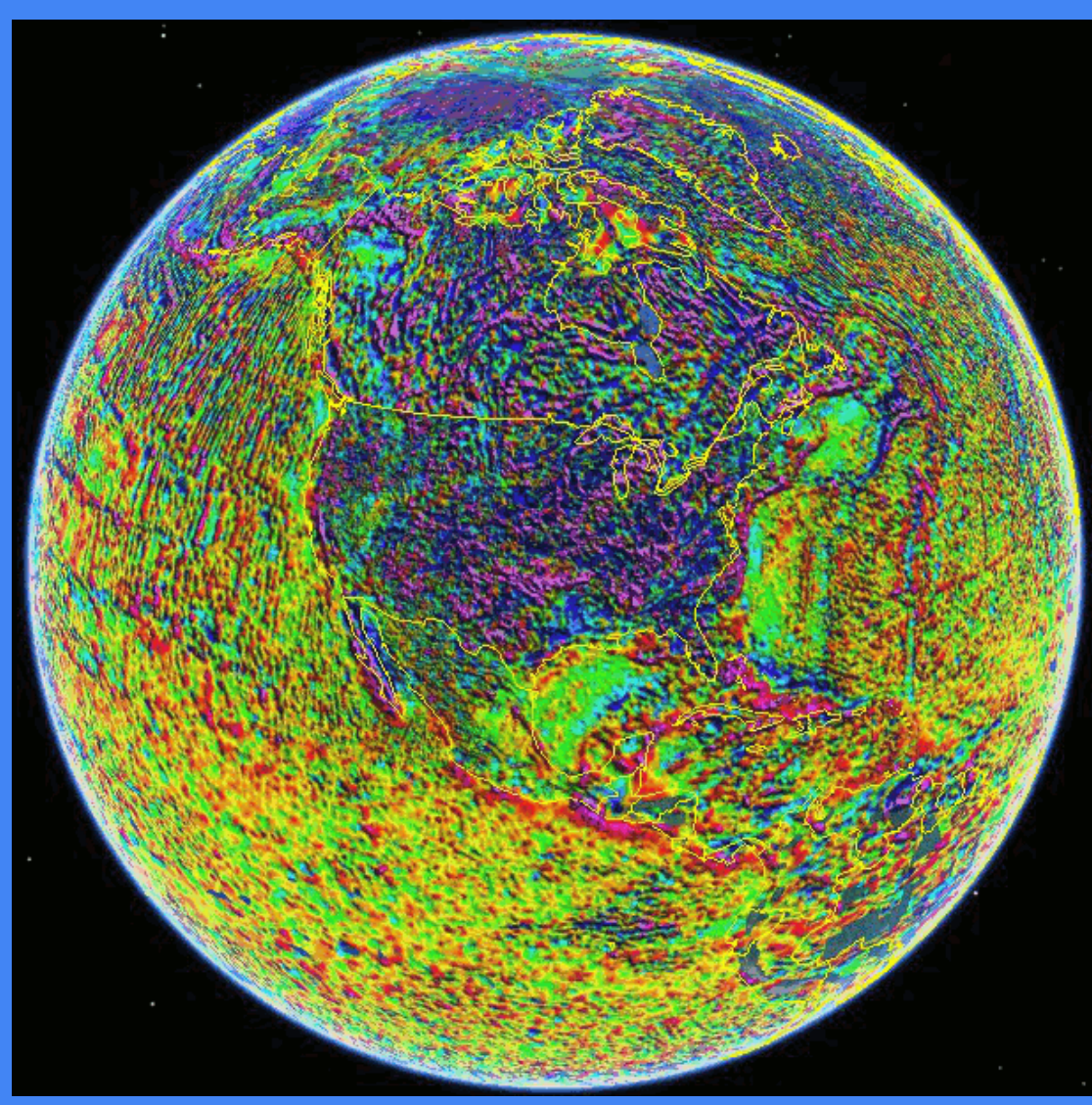

- www.ngdc.noaa.gov/geomag/emag2.html 


\section{EMAG2V3 - a few details}

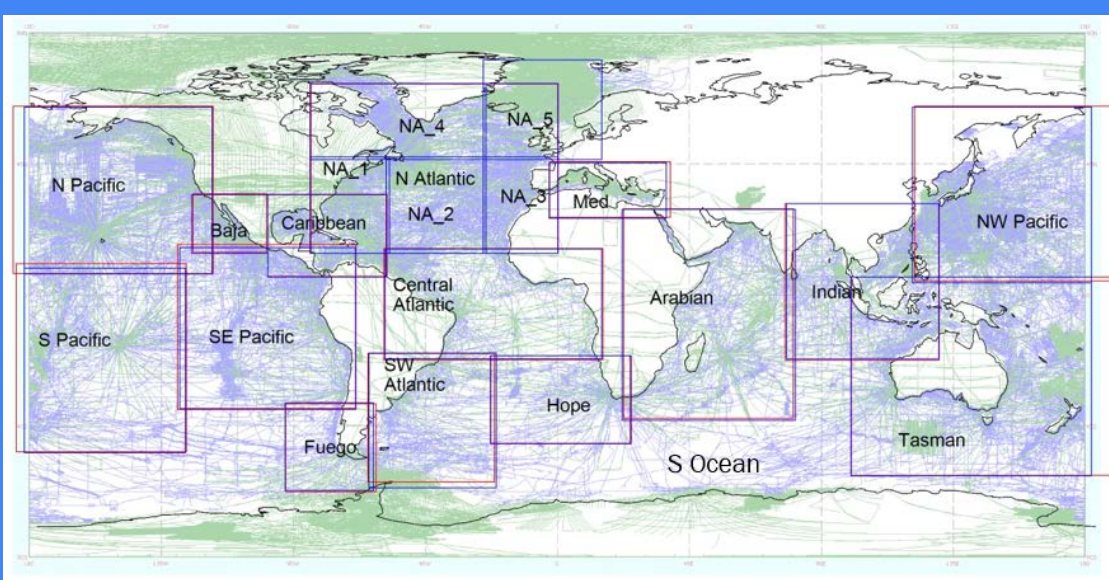

- Ocean coverage from new processing and leveling of NCE] (formerly NGDC) trackline coverage

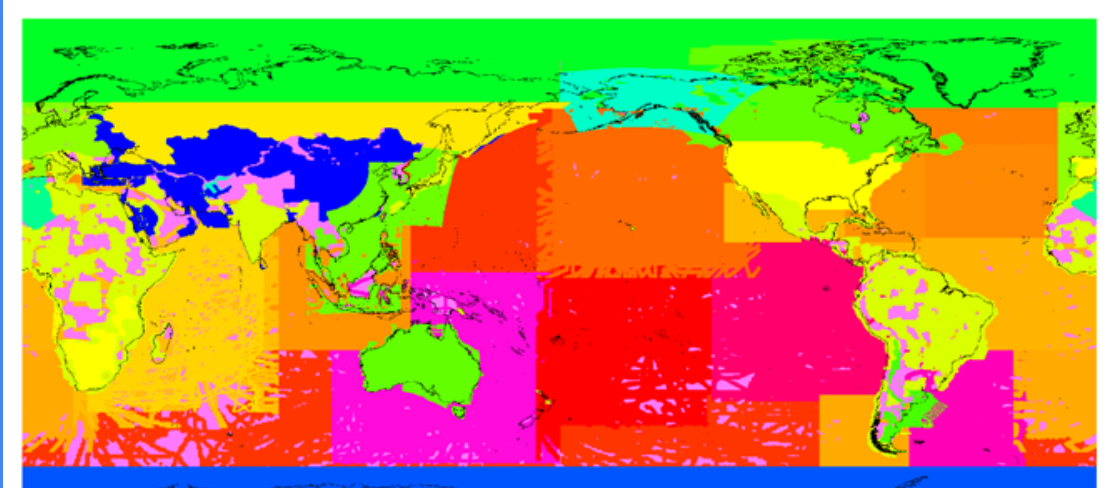

- Continents from best-available regional compilation grids 


\section{Magnetic transformations}

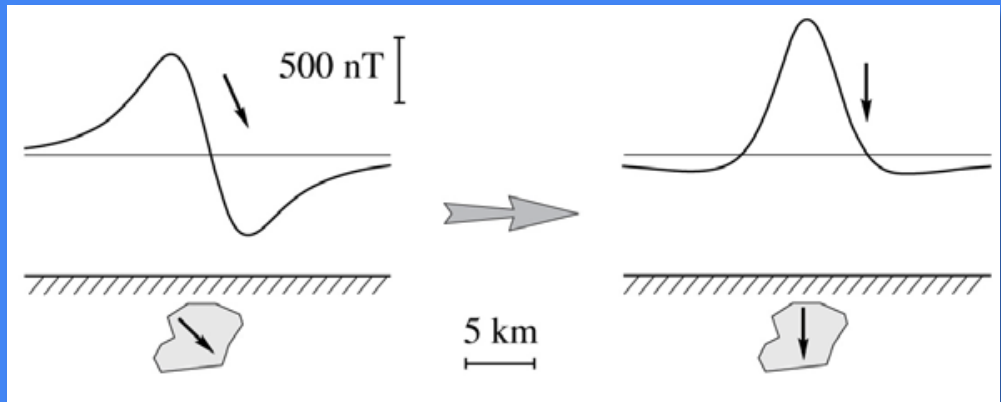

Reduction to the pole (RTP):

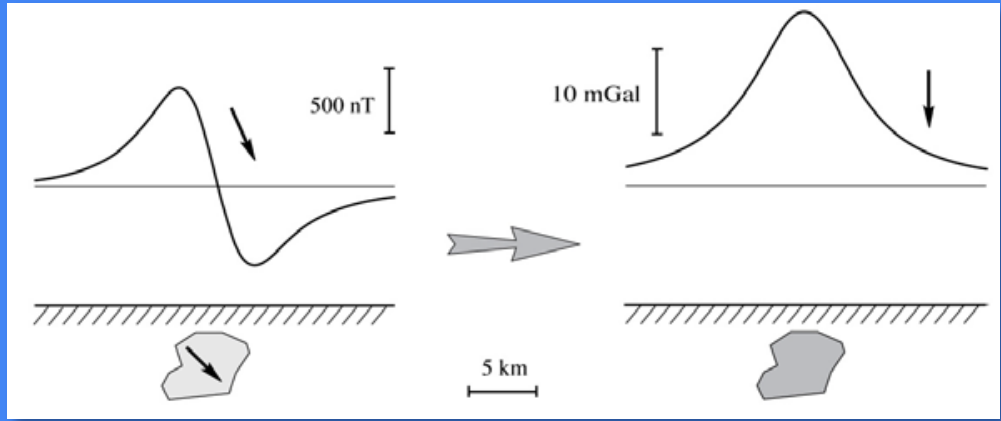

$F\left[h_{P}(x, y)\right]=F[h(x, y)] \frac{-2 \pi}{\boldsymbol{\theta}\left(k_{x}, k_{y}\right)}$

Blakely, 1995

Pseudogravity transformation:

$$
F\left[h_{P S G}(x, y)\right]=F[h(x, y)] \frac{-2 \pi}{\theta\left(k_{x}, k_{y}\right)} \frac{A}{|k|}
$$

$k=$ wavenumber,

$\theta\left(k_{x}, k_{y}\right)=$ a complicated function that depends only on the direction and magnitude of the Earth's magnetic field.

$A=\mathrm{a}$ constant based on the expected ratio of pseudo-density to magnetization 

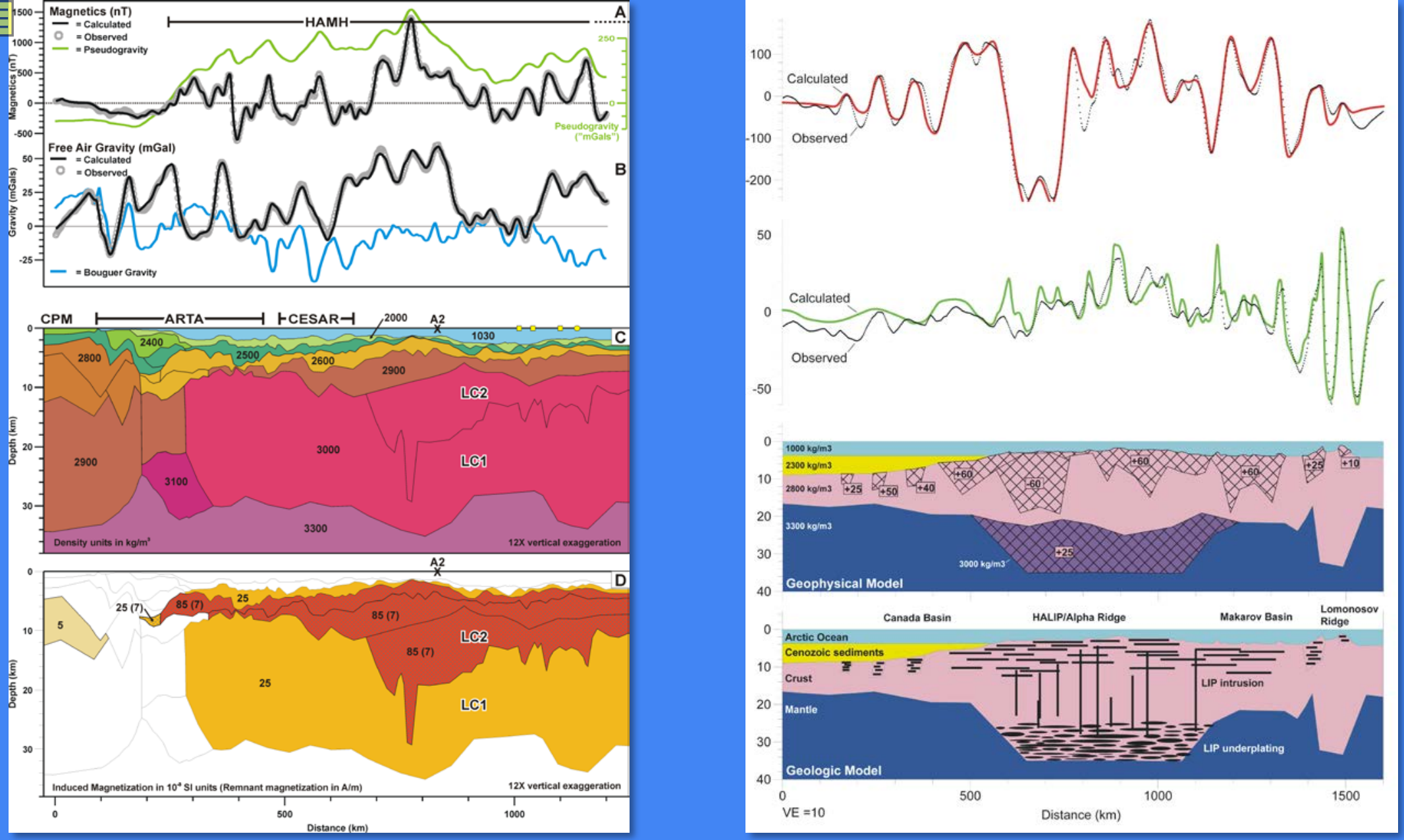

(Oakey and Saltus, 2016) 


\section{Magnetic Potential (pseudo-gravity)}

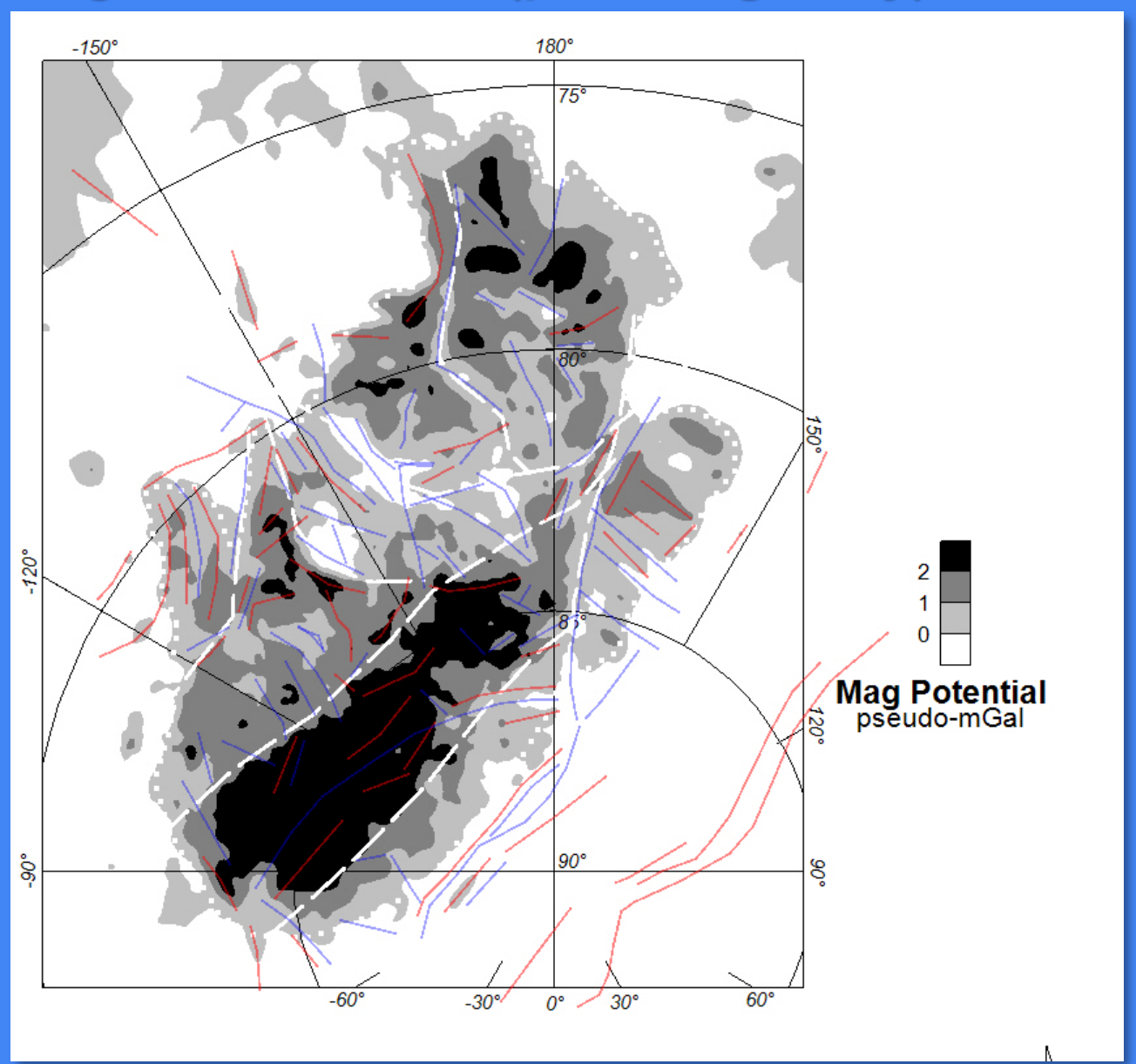

2 Plume

Events??? 


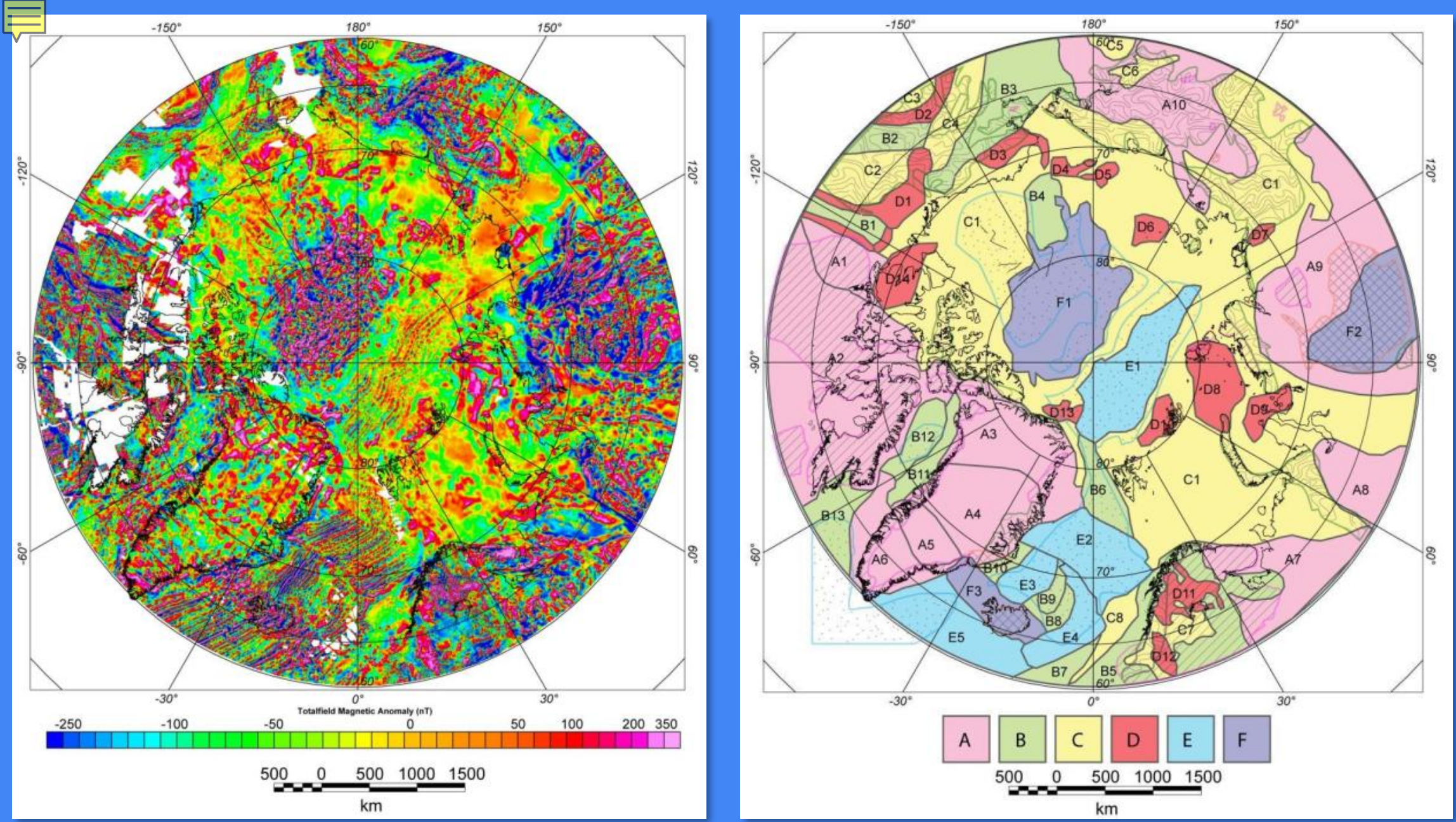

Arctic magnetic domains - F = LJP (Saltus et al, 2011) 


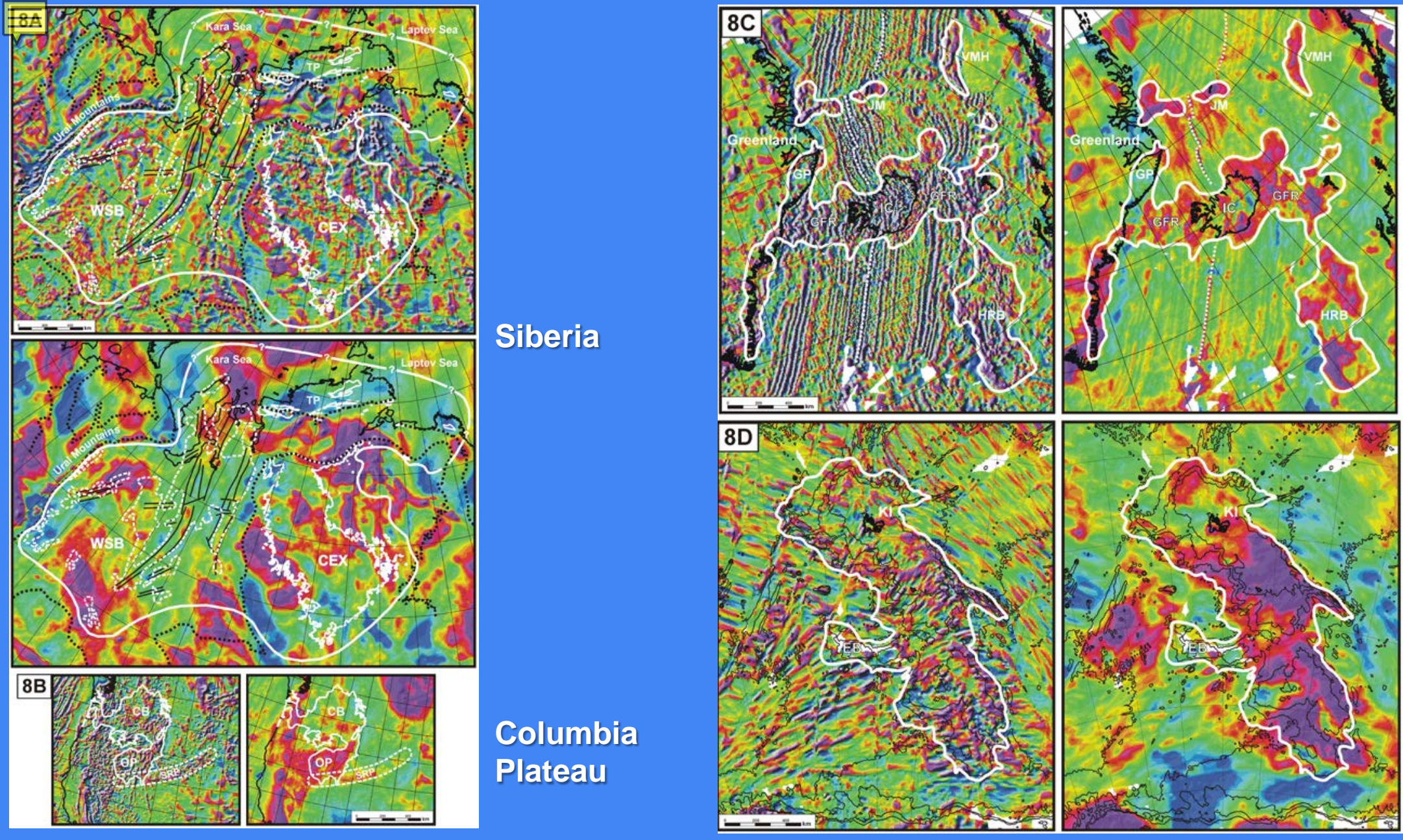

Some global examples based on careful study (Oakey and Saltus, 2016)

12 


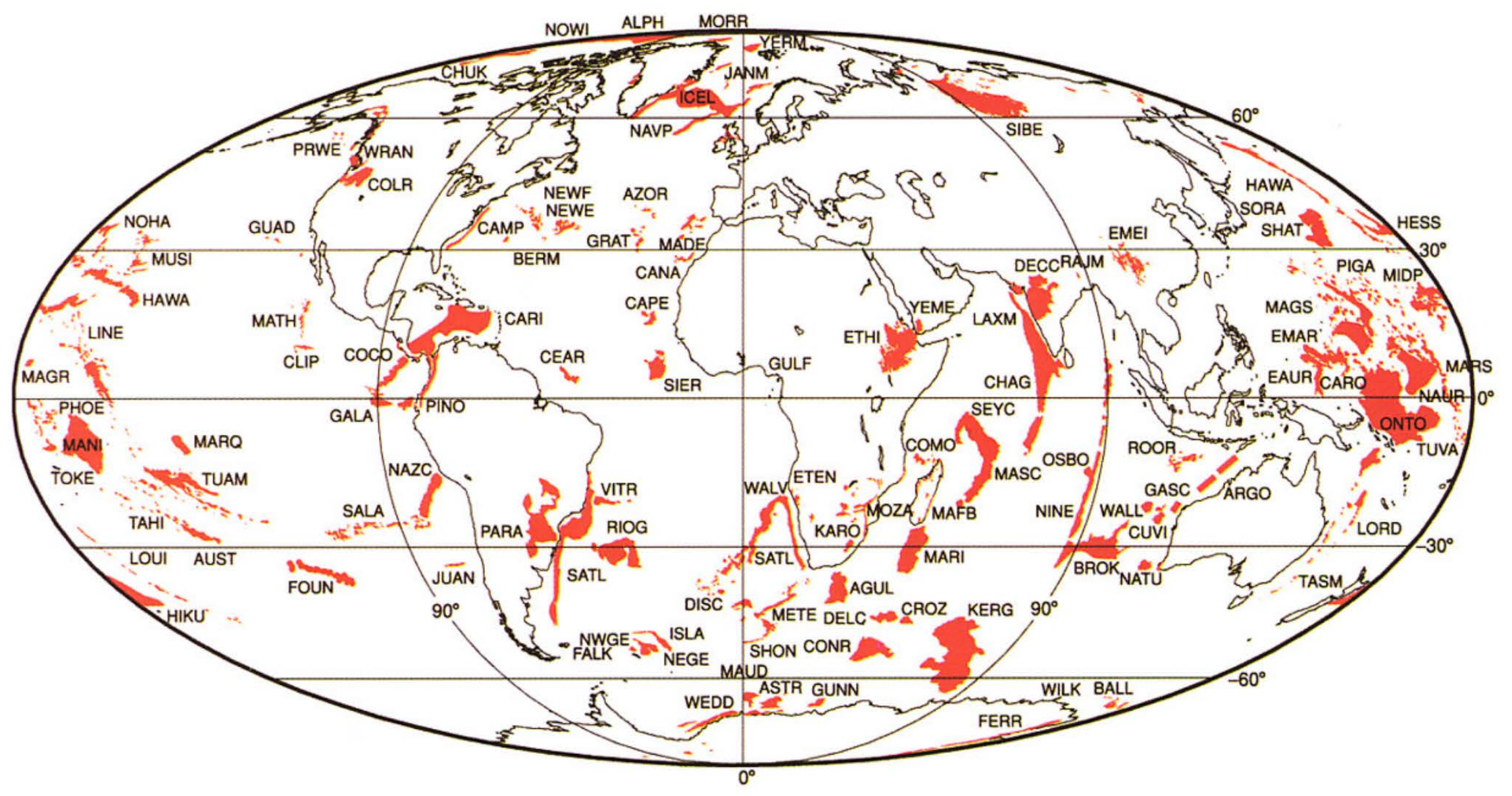




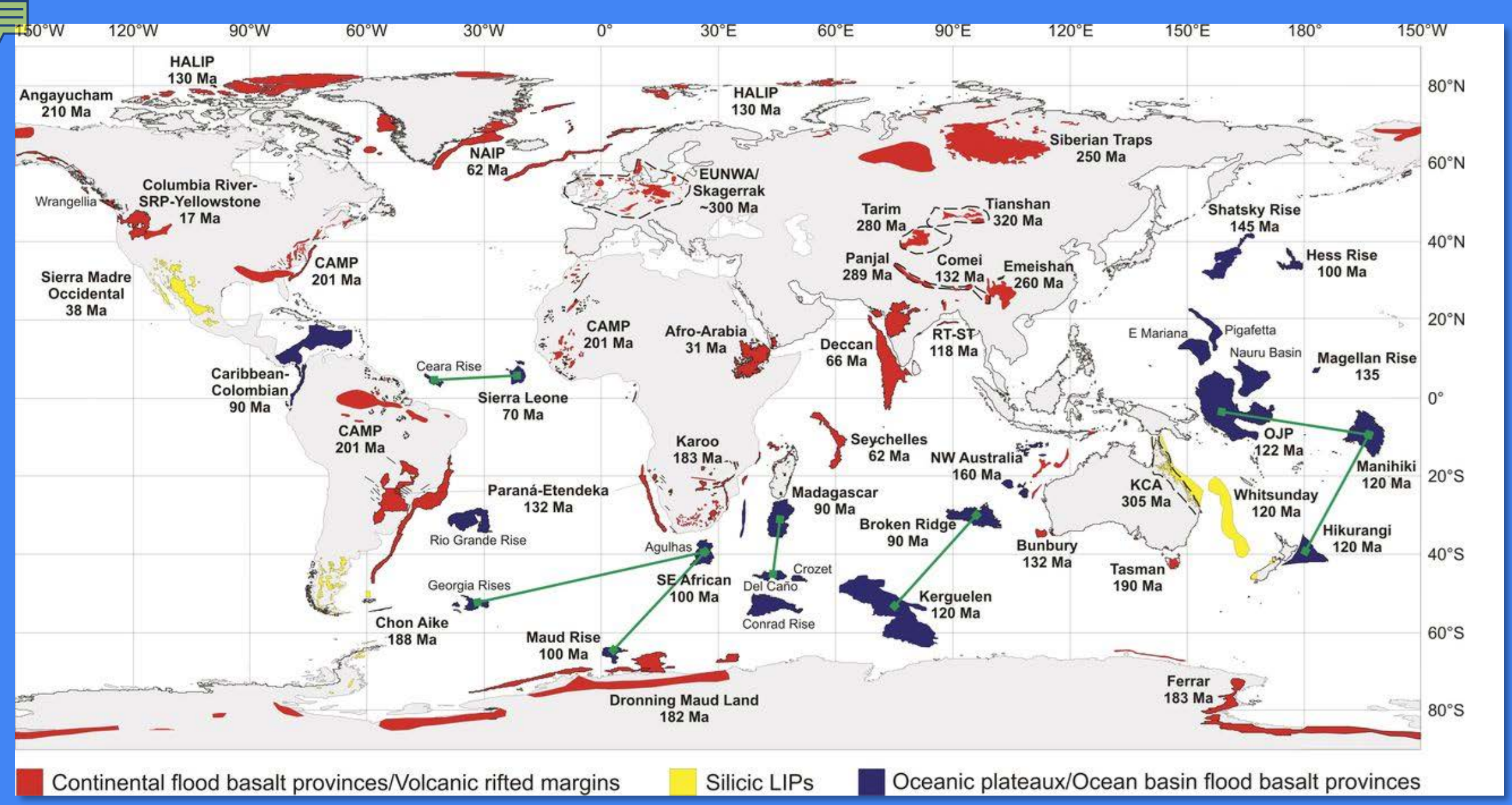

Bryan and Ferrari, 2013 


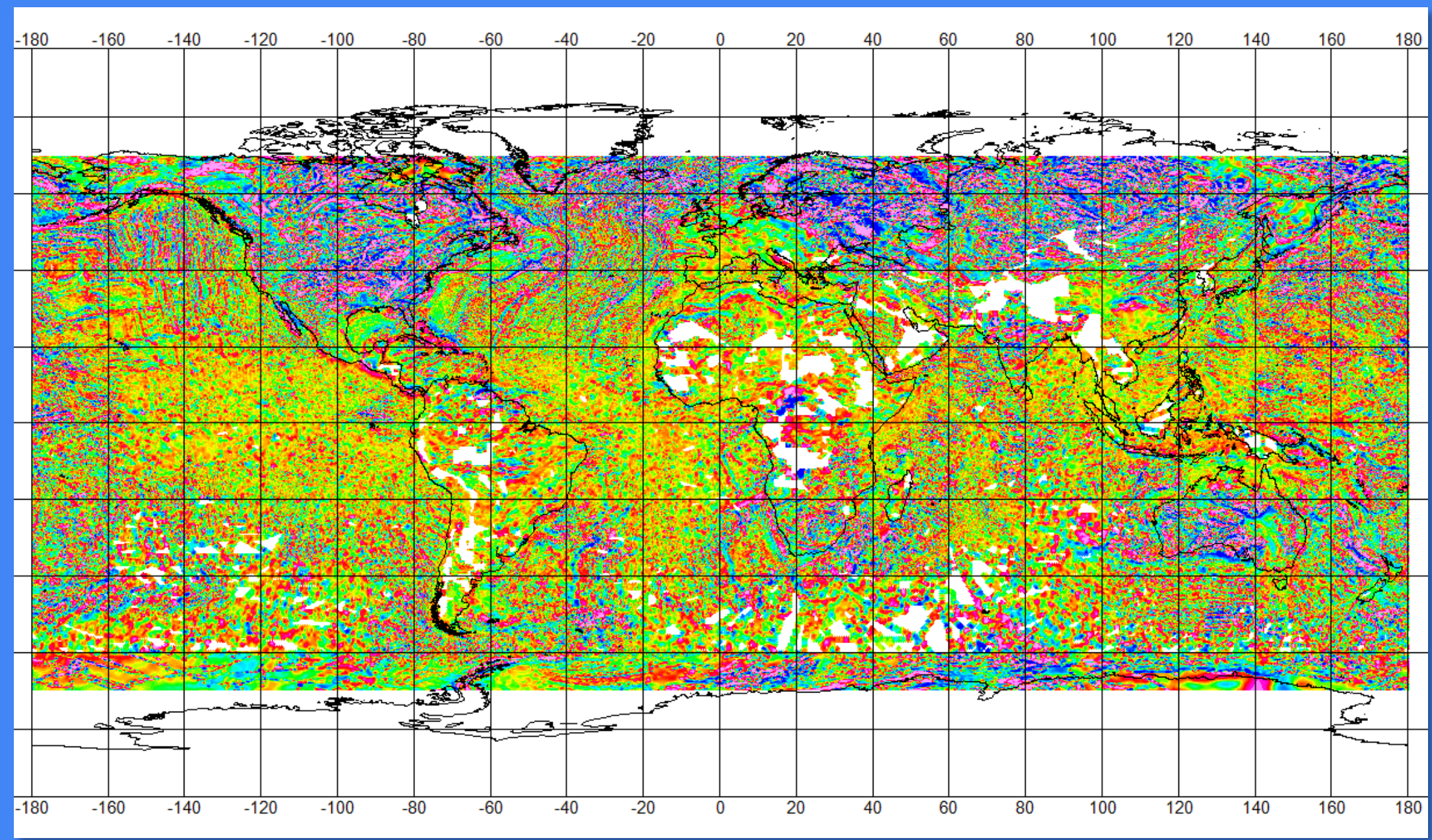

EMAG2v3 


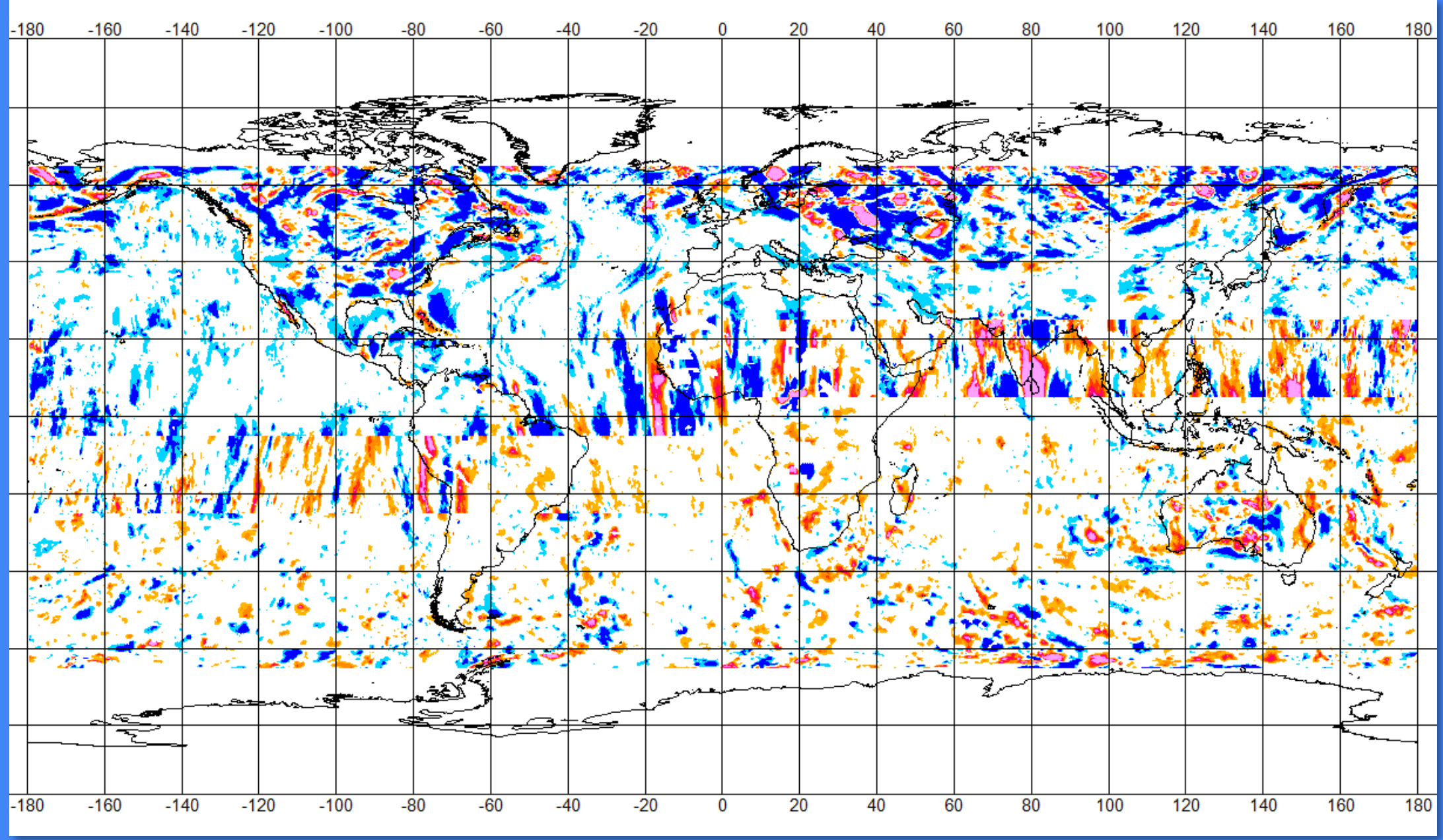

Pseudogravity (Beta version) from EMAG2v3 - Calculated using overlapping 40deg tiles 


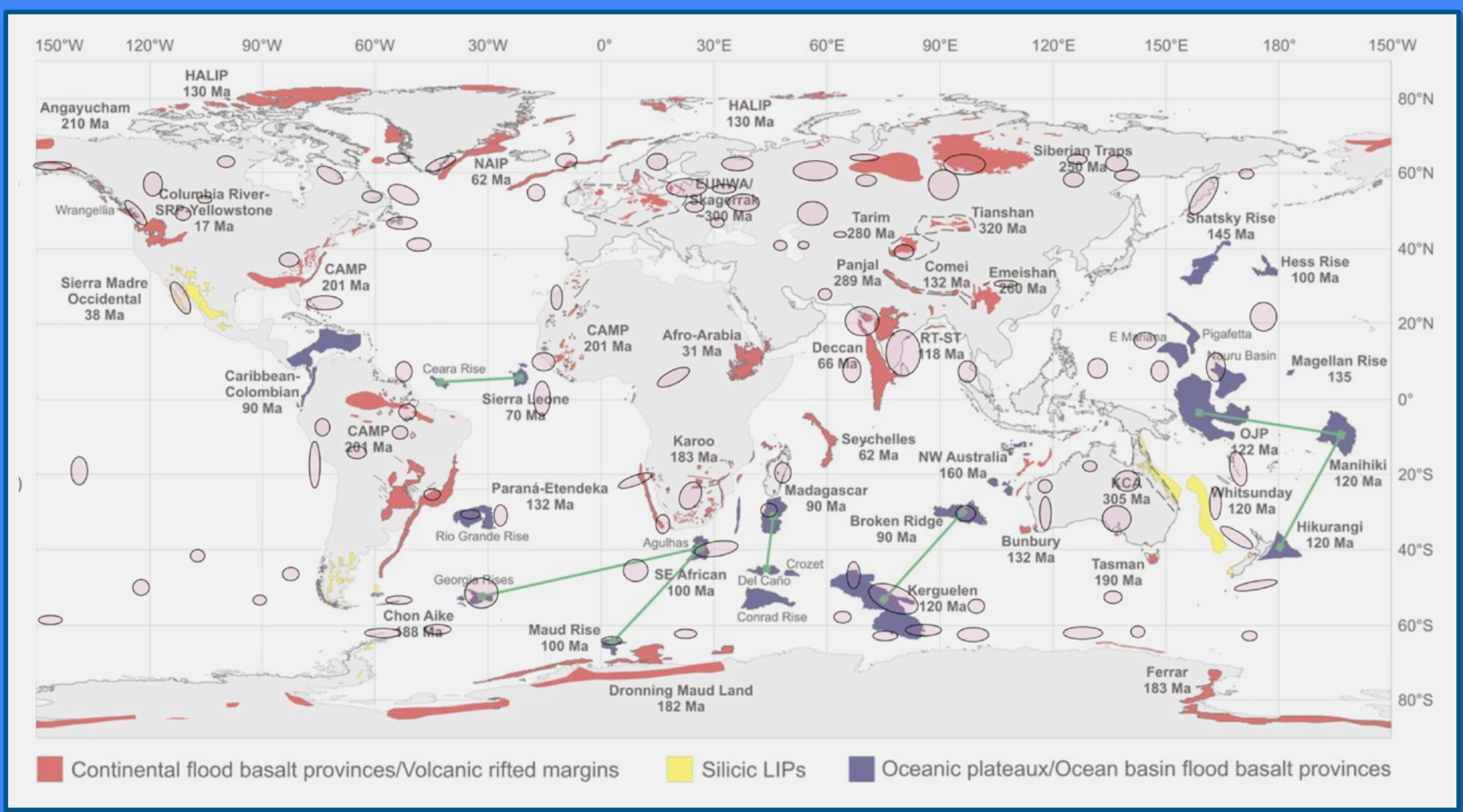

Drumroll please... Pseudogravity highs plotted on Bryan and Ferrari 2013 LIP map 


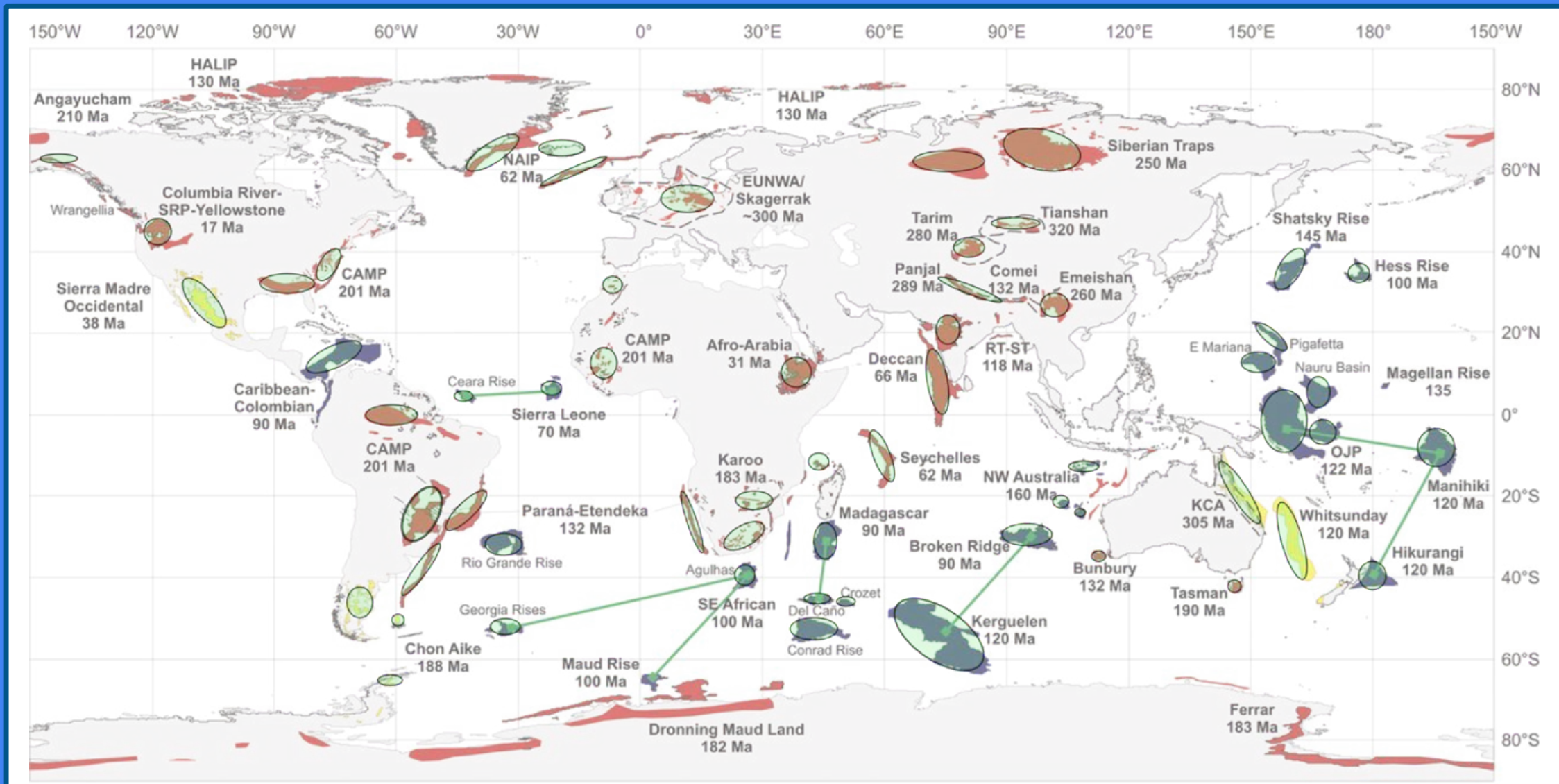

Continental flood basalt provinces/Volcanic rifted margins

Silicic LIPS

Oceanic plateaux/Ocean basin flood basalt provinces 


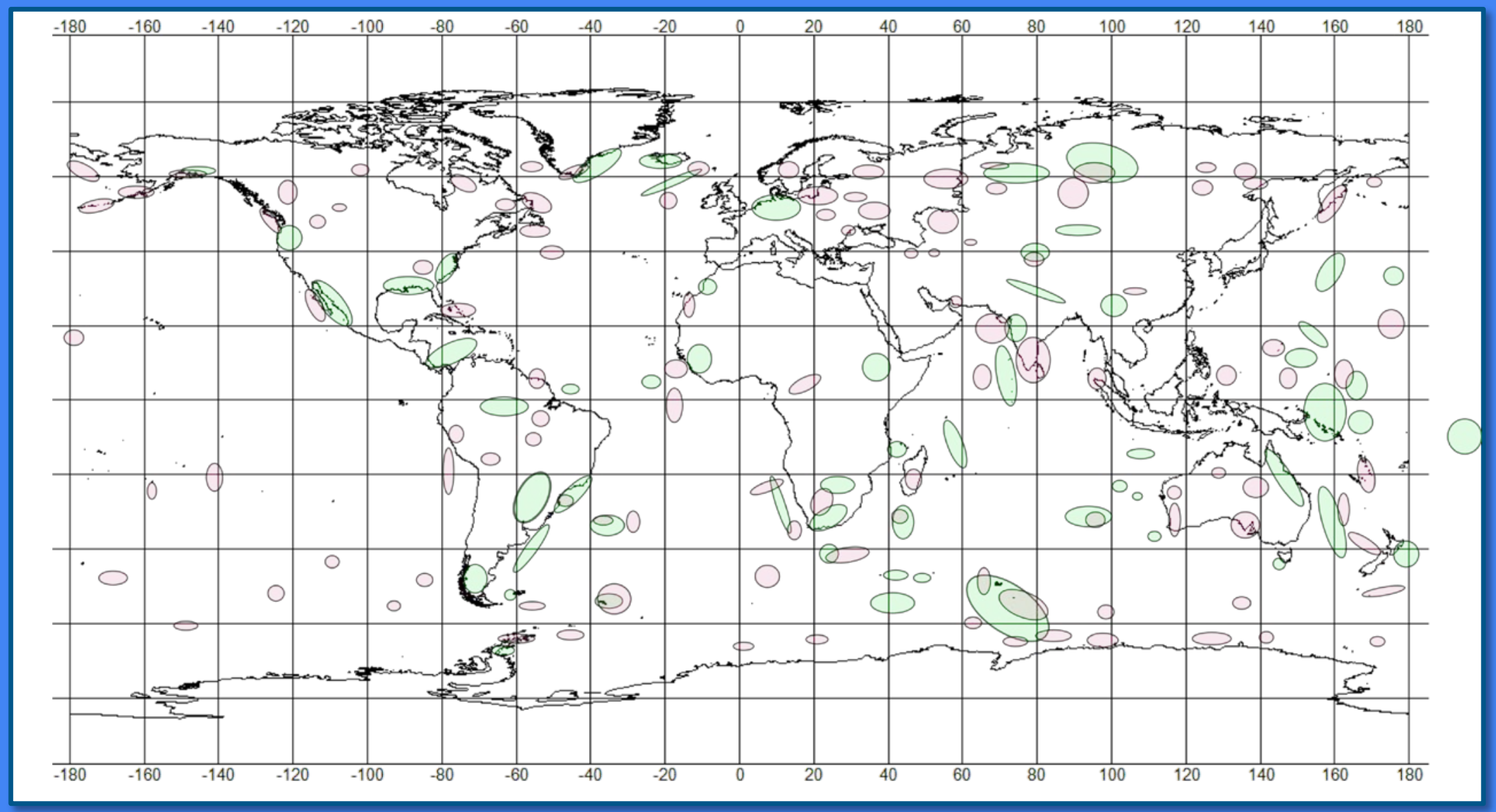

Pseudogravity highs and mapped LIPs 
Discussion and vote:

Is magnetic anomaly data diagnostic for LJP identification?

YES

- Reasonable expectation based on physical properties and mafic volumes

- Works in a number of well-documented cases

- Maybe it works reliably when you have good quality data
NO

- Not convinced that EMAG2 pseudogravity highs match global LIP polygons very well

- Geology is usually messier than theory would predict

- What about remanence, Curie depth, alteration, etc.?
DON'T KNOW YET

- EMAG2 resolution isn't sufficient yet

- Need a better map of global LJP polygons

- Need a better pseudogravity calculation

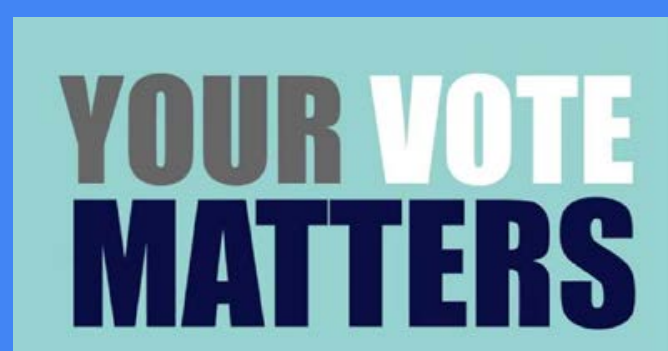




\section{CIRES GEOMAGNETIC RESOURCES}
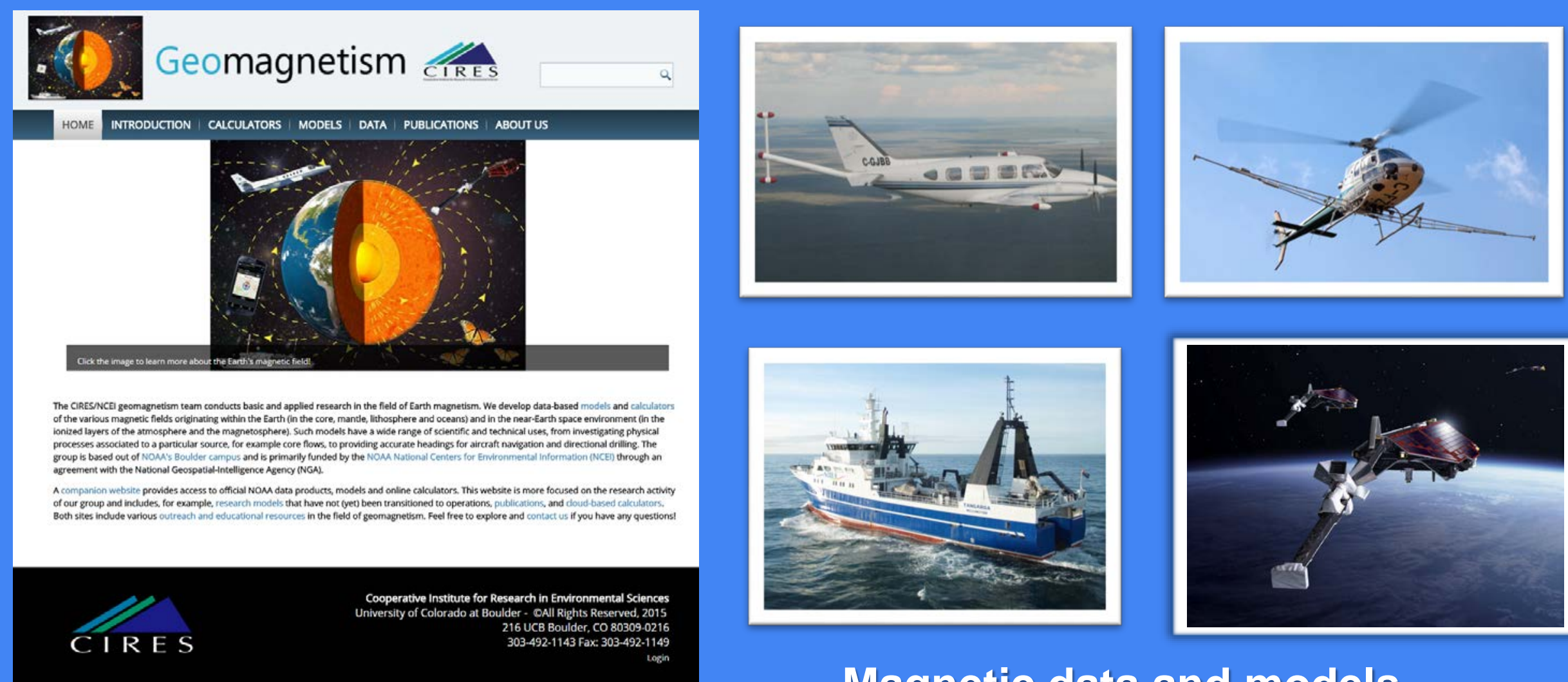

geomag.colorado.edu

Magnetic data and models 